\title{
Novel Bimetallic Dispersed Catalysts for Temperature-Programmed Coal Liquefaction
}

\author{
Technical Progress Report \\ January - March 1995
}

(Approved)

Chunshan Song, Stephen Kirby, Eckhardt Schmidt, and Harold H. Schobert

Fuel Science Program

Department of Materials Science and Engineering, 209 Academic Projects Bldg., The Pennsylvania State University

University Park, Pennsylvania, PA 16802

May 1995

Prepared for the U.S. Department of Energy under Contract No.

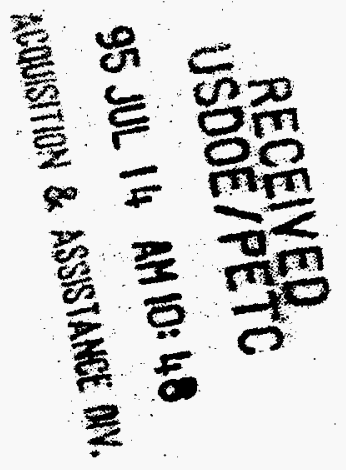

DE-AC22-92PC92122

\section{DISCLAIMER}

\begin{abstract}
This report was prepared as an account of work sponsored by an agency of the United States Government. Neither the United States Government nor any agency thereof, nor any of their employees, makes any warranty, express or implied, or assumes any legal liability or responsibility for the accuracy, completeness, or usefuiness of any information, apparatus, product, or process disclosed, or represents that its use would not infringe privately owned rights. Reference herein to any specific commercial product, process, or service by trade name, trademark, manufacturer, or otherwise does not necessarily constitute or imply its endorsement, recommendation, or favoring by the United States Government or any agency thereof. The views and opinions of authors expressed herein do not necessarily state or reflect those of the United States Government or any agency thereof.
\end{abstract}




\section{Table of Contents}

\section{Abstract}

Technical Progress 3

Hydrodeoxygenation of O-containing Polycyclic Model Compounds Using Novel Organometallic Catalyst Precursors.

Introduction 3

Experimental Section $\quad 3$

Results and Discussion $\quad 4$

$\begin{array}{ll}\text { Conclusions } & 10\end{array}$

$\begin{array}{ll}\text { References cited } & 11\end{array}$

Activity and Selectivity of Fe Catalysts from Organometallic and Inorganic

Precursors for Hydrocracking of 4-(1-Naphthylmethyl) Bibenzyl

Introduction 12

$\begin{array}{ll}\text { Experimental Section } & 12\end{array}$

$\begin{array}{ll}\text { Results and Discussion } & 13\end{array}$

$\begin{array}{ll}\text { Hydrocracking of NMBB } & 13\end{array}$

$\begin{array}{ll}\text { Product Distribution } & 16\end{array}$

$\begin{array}{ll}\text { Possible Reaction Mechanism } & 17\end{array}$

$\begin{array}{ll}\text { Conclusions } & 18\end{array}$ 


\section{DISCLAIMER}

This report was prepared as an account of work sponsored by the United States Government. Neither the United States Government nor any agency thereof, nor any of their employees, makes any warranty express or implied, or assumes any legal liability or responsibility for the accuracy, completeness, or usefulness of any information, apparatus, product, or process disclosed, or represents that its use would not infringe privately owned rights. Reference herein to any specific commercial product, process or service by trade name, mark manufacturer, or otherwise, does not necessarily constitute or imply its endorsement, recommendations, or favoring by the United States Government or any agency thereof. The views and opinions of authors expressed herein do not necessarily state or reflect those of the United States Government or any agency thereof.

\section{ACKNOWLEDGEMENTS}

This on-going project is supported by the U.S. Department of Energy, Pittsburgh Energy Technology Center, in Advanced Coal Research Program. Dr. U. Rao is the DOE/PETC Project Manager. Dr. H.H. Schobert and Dr. C. Song are the Co-Principal Investigators at Penn State. The authors wish to express their appreciation to Dr. U. Rao of DOE/PETC for his support of this effort. The authors would also like to thank Mr. R.M Copenhaver for the fabrication of tubing bomb reactors. 


\begin{abstract}
Coal liquefaction involves cleavage of methylene, dimethylene and ether bridges connecting polycyclic aromatic units and the reactions of various oxygen functional groups. The selected compound for model coal liquefaction reactions are 4-(1-naphthylmethyl)bibenzyl (NMBB) and anthrone. This report describes 1 ) hydrodeoxygenation of O-containing polycyclic model compounds using novel organometallic catalyst precursors; and 2) activity and selectivity of dispersed Fe catalysts from organometallic and inorganic precursors for hydrocracking of 4-(1-Naphthylmethyl) bibenzyl.
\end{abstract}

For hydrodeoxygenation, model compound studies were performed using multi-ring systems, or those of comparable molecular weight, to investigate the capabilities of the dispersed catalysts. The model compounds selected include anthrone (carbonyl); dinaphthyl ether (arylaryl ether); xanthene (heterocyclic ether); and 2,6-di-t -butyl-4-methylphenol (hydroxyl). The catalyst precursors used were (NH4) ${ }_{2} \mathrm{MoS}_{4}(\mathrm{ATTM}),\left[\mathrm{Ph}_{4} \mathrm{P}\right]_{2}\left[\mathrm{Ni}\left(\mathrm{MoS}_{4}\right)_{2}\right](\mathrm{Ni}-\mathrm{Mo} 1)$ and $\mathrm{Cp}_{2} \mathrm{Co}_{2} \mathrm{Mo}_{2}(\mathrm{CO})_{2} \mathrm{~S} 4$ (CoMo-T2). Reactions were performed in a $22 \mathrm{ml}$ capacity microreactor (with $0.5 \mathrm{~g}$ model compound under $1000 \mathrm{psi} \mathrm{H}_{2}$ ) at $300^{\circ} \mathrm{C}, 350^{\circ} \mathrm{C}$ and $400^{\circ} \mathrm{C}$ for 30 minutes.

From the non-catalytic data shown there is a clear order of starting material reactivity : 2,6-di-t-butyl-4-methylphenol $>$ anthrone $>$ dinaphthyl ether $>$ xanthene. However, the reactivity order of the oxygen functionalities in the presence of the various catalysts is different. For noncatalytic conditions the order appears to be : carbonyl > aryl-aryl ether $»$ substituted phenol $\approx$ heterocyclic ether. In the presence of ATTM this sequence changes slightly to : carbonyl > substituted phenol $\approx$ aryl-aryl ether $~$ heterocyclic ether and for reactions involving CoMo-T2 the reactivity order appears to be : carbonyl $>$ aryl-aryl ether $>$ heterocyclic ether $>$ substituted phenol.

These differences in reactivity order emphasize the effect of the nature of the oxygen functionality on the deoxygenating capabilities of the catalysts and that different catalysts can have different roles in promoting hydrodeoxygenation and reduction, depending on the nature of the starting material. They also highlight the undesirability of phenolic and heterocyclic ether structures in liquefaction systems. Both these structures types are quite unreactive under liquefaction conditions and any reaction has a tendency to form high yields of single-ring phenols.

When applied to coals, these findings suggest that coals differing from each other in the form of which oxygen functional groups are dominant, may show quite different kinds of liquefaction products, depending on which catalyst precursor was chosen. 
To examine what determines the activity and selectivity of $\mathrm{Fe}$ catalysts for hydrogenation and hydrocracking, various molecular precursors with $\mathrm{Fe}$ in different chemical environments have been tested in this work to help understand the influence of precursor structure and the effect of sulfur addition on the activity and selectivity of resulting $\mathrm{Fe}$ catalysts in model reactions of 4-(naphthylmethyl)bibenzyl (NMBB). We have examined various precursors, including a thiocubane type cluster $\mathrm{Cp}_{4} \mathrm{Fe}_{4} \mathrm{~S}_{4}$, a cyclopentadienyliron dicarbonyl dimer $\mathrm{Cp}_{2} \mathrm{Fe}_{2}(\mathrm{CO})_{4}$, ferrocene $\mathrm{Cp}_{2} \mathrm{Fe}$, a series of carbonyl precursors including $\mathrm{Fe}(\mathrm{CO})_{5}, \mathrm{Fe}_{2}(\mathrm{CO}) 9$, and $\mathrm{Fe}_{3}(\mathrm{CO})_{12}$, and superfine iron oxide with average particle size of $30 \AA$ (SFIO). For testing various Fe catalyst precursors, runs with NMBB were carried out in $33 \mathrm{~mL}$ reactor using $0.78 \mathrm{mmol} \mathrm{NMBB}$ in n-tridecane solvent at $400^{\circ} \mathrm{C}$ for $30 \mathrm{~min}$, in the presence of a Fe catalyst precursor (2.11 wt \% Fe based on NMBB).

The particles from $\mathrm{Cp}_{2} \mathrm{Fe}_{2}(\mathrm{CO})_{4}$ showed the highest activity among all the precursors examined in the absence of added sulfur. The activity of catalysts from $\mathrm{Fe}$ carbonyls decreased with increasing number of irons in the carbonyl compounds: $\mathrm{Fe}(\mathrm{CO})_{5}>\mathrm{Fe}_{2}(\mathrm{CO}) 9$ $>\mathrm{Fe}_{3}(\mathrm{CO}) 12$; adding sulfur increased their activity but their activities rank the same both with and without sulfur addition. Surprisingly, $\mathrm{Cp}_{4} \mathrm{Fe}_{4} \mathrm{~S}_{4}$ exhibited the lowest activity, although it has the $\mathrm{S}$-to-Fe ratio closest to pyrrhotite ( $\mathrm{Fe}_{1-\mathrm{x}} \mathrm{S}$, where $\mathrm{X}=0$ to 0.12 ) which is thought to be the active phase. The nano-scale SFIO particles performed at an activity level similar to that of $\mathrm{Fe}_{2}(\mathrm{CO}) 9$ in the absence of sulfur, but afforded the highest NMBB conversion when $\mathrm{S}$ was added. Ferrocene is more effective in hydrocracking reactions of $\mathrm{NMBB}$ than the inorganic iron complex $\mathrm{FeSO}_{4} \cdot 7 \mathrm{H}_{2} \mathrm{O}$. Sulfur added to iron sulfate had the expected beneficial effect on NMBB conversion. But sulfur added to ferrocene decreased the activity of resulting catalyst. The other iron containing organometallic complex that showed a similar trend in conversion after sulfur addition was $\mathrm{Cp}_{2} \mathrm{Fe}_{2}(\mathrm{CO})_{4}$. Both complexes have cyclopentadienyl ligands as common features. Another precursor with $\mathrm{Cp}$-functionalities and sulfur in the precursor molecule $\left(\mathrm{Cp}_{4} \mathrm{Fe}_{4} \mathrm{~S}_{4}\right)$ showed very low activity too. There is apparently a negative correlation between the conversion of iron containing complexes and the presence of cyclopentadienyl/sulfur units.

The present results showed that some iron containing catalysts have higher activity in the sulfur-free form, contrary to conventional wisdom. Adding sulfur to Fe precursors with $\mathrm{Cp}$-ligands decreased the activity of the resulting catalyst. This is in distinct contrast to the cases with iron pentacarbonyl and superfine $\mathrm{Fe}_{2} \mathrm{O}_{3}$, where $\mathrm{S}$ addition increased their catalytic activity substantially. A positive correlation between sulfur addition and increased activity can be seen, but a reversed trend between Fe cluster size and hydrocracking conversion could be observed, for carbonyl-type Fe precursors. It is apparent that the activity and selectivity of Fe catalysts for NMBB conversion depends strongly on both the type of ligand environment, the oxidation state and the number of intermetal bonds in the molecular precursor. 


\section{Technical Progress}

\section{Hydrodeoxygenation of O-containing Polycyclic Model Compounds Using Novel Organometallic Catalyst Precursors.}

\section{INTRODUCTION}

Oxygenated compounds are present in virtually all coals [1]. Phenols (and related hydroxyl compounds) have been identified as components of coal-derived distillates [2,3]. Ethers and related compounds, connecting structural units within the coal matrix, have been proposed as sites for the depolymerization of the coal [4] and also ethers, together with carboxyls and phenolics, have been implicated in the facilitation of retrogressive, crosslinking, repolymerization reactions $[5,6]$.

Low-rank coals (i.e. lignites and subbituminous coals ) include significantly more oxygen-containing groups than coals of higher rank [7]. With the increase in the extraction of lower rank coals in the U.S. and research into their use as liquefaction feedstocks [5,8,9], the importance of oxygen functionality removal from coal and coal-derived liquids is all the more apparent.

The removal of these functionalities from the distillate products of coal liquefaction can be both complicated and expensive, and often leads to substantial reductions in distillate yields [3]. Therefore, deoxygenation during the liquefaction process would be beneficial. This goal may be attainable with the use of sulphided bimetallic catalysts dispersed onto the coal using an organometallic precursor $[10,11]$.

Model compound studies using multi-ring systems, or those of comparable molecular weight, were performed to investigate the capabilities of these catalysts. The model compounds selected represent a variety of oxygen functionalities, possibly present in coals of differing rank [12-14], contained within polycyclic systems. They include: anthrone (carbonyl); dinaphthyl ether (aryl-aryl ether); xanthene (heterocyclic ether); and 2,6-di-t -butyl-4-methylphenol (hydroxyl).

\section{EXPERIMENTAL}

All experiments were performed in a $22 \mathrm{ml}$ capacity microreactor. A $0.5 \mathrm{~g}$ sample of model compound was loaded into the reactor. Solvent was added in a 1:2 weight ratio to model compound and catalyst precursors were added at $2.46 \mathrm{~mol} \%$ concentration (unless otherwise 
stated). The catalyst precursors used were $\left(\mathrm{NH}_{4}\right)_{2} \mathrm{MoS}_{4}(\mathrm{ATTM}),\left[\mathrm{Ph}_{4} \mathrm{P}\right]_{2}\left[\mathrm{Ni}(\mathrm{MoS})_{2}\right](\mathrm{Ni}$ $\mathrm{Mo1}$ ) and $\mathrm{Cp}_{2} \mathrm{Co}_{2} \mathrm{Mo}_{2}(\mathrm{CO})_{2} \mathrm{~S} 4$ (CoMo-T2).

Air was removed by flushing the reactor three times with $\mathrm{H}_{2}$ to $1000 \mathrm{psi}$. The reactor was then repressurized to $1000 \mathrm{psi} \mathrm{H}_{2}$. Reactions were performed at $300^{\circ} \mathrm{C}, 350^{\circ} \mathrm{C}$ and $400^{\circ} \mathrm{C}$ for 30 minutes. All reactions were carried out in a fluidized sand bath equipped with a vertical oscillator driving at a setting of 55 ( -250 strokes per minute). At the end of the reaction the microreactor was quenched in cold water.

Tridecane $(0.25 \mathrm{~g})$ was added to the microreactor as an internal standard. The microreactor contents were then extracted with acetone and diluted for analysis.

Capillary gas chromatography (GC) connected to a flame ionization detector (Perkin Elmer-8500) and gas chromatography / mass spectrometry (Hewlett Packard-5890) were used for the quantitative and qualitative analysis of the product distribution, respectively.

\section{RESULTS AND DISCUSSION}

Product distributions have been grouped as oxygen-containing and deoxygenated for the purposes of this article. The conversions of anthrone, dinaphthyl ether, xanthene and 2,6-ditbutyl-4-methylphenol are shown in Figures 1-4, and the product distribution of dinaphthyl ether is given in Table 1.

Generally, the addition of any catalyst to a system under the conditions studied increases the total conversion. For example, at $400^{\circ} \mathrm{C}$ dinaphthyl ether undergoes $26 \%$ thermal conversion; this yield is increased to $72 \%$ in the presence of ATTM, 88.5\% with Ni-Mol, and $100 \%$ using CoMo-T2. However, any improvement in the product quality, especially deoxygenation and ring reduction, in the presence of these catalysts is also important, and the variation of these factors for the different oxygen functional groups will be the main focus of this discussion.

\section{Anthrone}

Under non-catalytic conditions anthrone converts to anthracene through thermal reaction of the carbonyl oxygen. Anthracene then reacts further to form a variety of hydrogenated ring species, such as di- and tetrahydroanthracene.

In the presence of ATTM, the formation of oxygen-containing compounds in the products at $350^{\circ} \mathrm{C}$ and $400^{\circ} \mathrm{C}$ (substituted naphthols and phenols) suggest hydrogenation of the carbonyl oxygen to a hydroxyl group before extensive conversion to anthracene. Reduction in the yields of these oxygen functionalities in the ATTM reaction at $400^{\circ} \mathrm{C}$ may indicate the possibility of an increase in the conversion of these species to non-oxygenated products. 
Conversion of anthrone to oxygen-free products is increased considerably using the CoMo-T2 catalyst precursor. This implies that CoMo-T2 has the capability to increase the conversion of carbonyls without additional phenol or naphthol production. This may be achieved by either rapid $\mathrm{C}=\mathrm{O}$ cleavage prior to ring hydrogenation, rapid phenol conversion to oxygen-free products, or by the prevention of initial hydroxyl group formation. From the reactions of 2,6-di-t-butyl-4-methylphenol with CoMo-T2, it can be seen that this catalyst, although removing some hydroxyl functionality, does not promote the ready conversion of phenols to non-oxygen containing species.

Variations in the oxygen-free products of anthrone conversion are also apparent for the different catalyst precursors. Ni-Mol appears to promote the formation of 1,2,3,4tetrahydroanthracene (THA), whereas CoMo-T2 demonstrates the facilitation of 9,10dihydroanthracene (DHA) production. ATTM seems to have equal affinity for the formation of both products. Ni-Mol and ATTM both exhibit an increase in the formation of 1,2,3,4,5,6,7,8octahydroanthracene $(\mathrm{OHA})$ at $400^{\circ} \mathrm{C}(0 \%$ under catalyst-free conditions to $11.8 \%$ and $11.3 \%$ respectively), which only appears in very low yields with CoMo-T2 $(1.5 \%)$. This reduction in OHA yield for the CoMo-T2 precursor is comparable to increases in anthracene and DHA production, suggesting selective hydrogenation of the 9- and 10- positions (i.e. the carbonyl carbon).

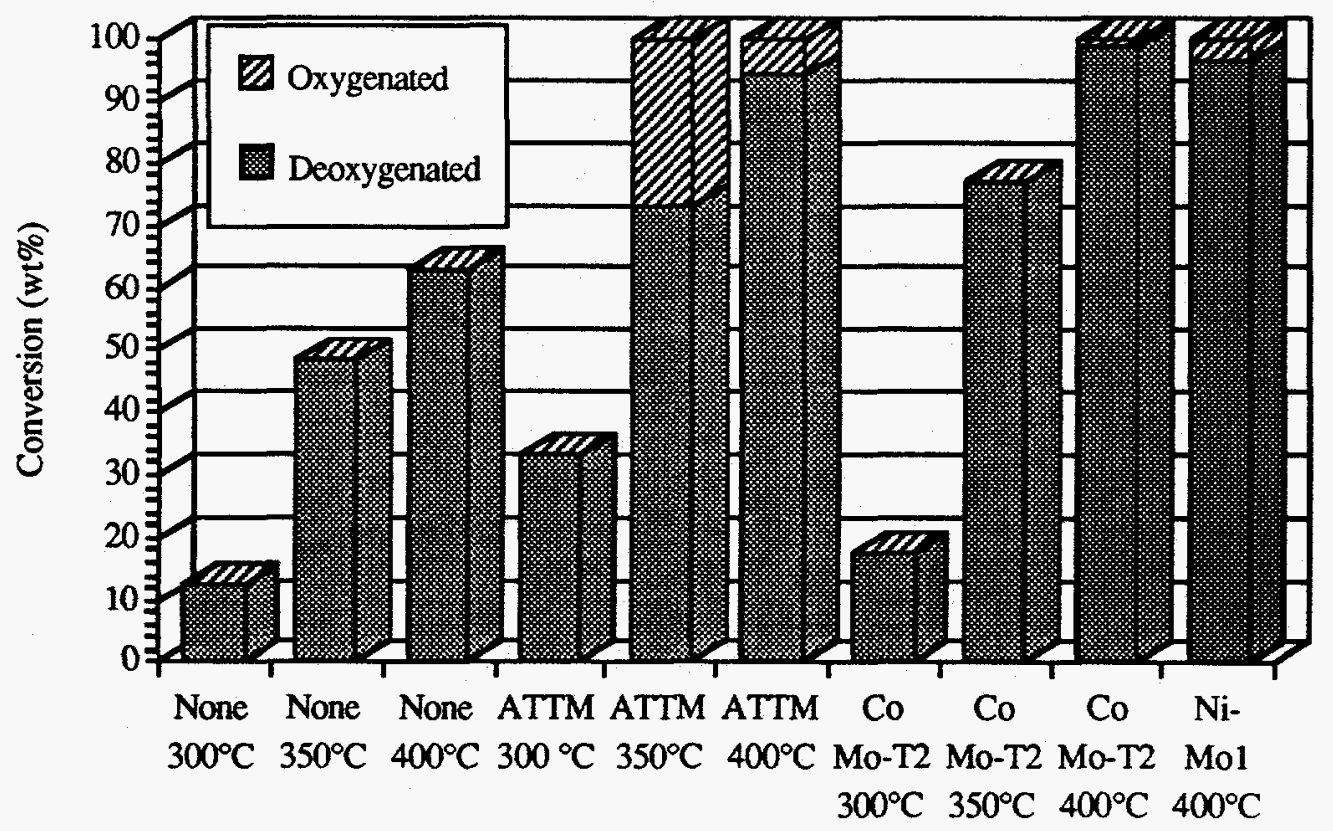

Figure 1. Yield of oxygenated and deoxygenated products of anthrone as a function of temperature and catalyst precursor. 


\section{Dinaphthyl Ether}

Under non-catalytic conditions naphthalene is the major product of dinaphthyl ether (DNE) hydrogenation, with low yields of 2-naphthol, although total conversion is very small $(26 \%)$. Oxygen functionality removal is increased in the presence of all the catalyst precursors, although to a lesser extent than for anthrone.

ATTM increases DNE conversion to oxygen-free products $\left(63.6 \%\right.$ at $\left.400^{\circ} \mathrm{C}\right)$ with the balance of the products being phenols, naphthols $(1.8 \%)$ and ring-reduced derivatives of the starting material. Phenol and naphthol yields decrease from $350^{\circ} \mathrm{C}$ to $400^{\circ} \mathrm{C}$, again implying that ATTM facilitates hydroxyl group removal.

High conversions to tetralin and naphthalene are achieved in the presence of CoMo-T2 $\left(51.6 \%\right.$ and $40.2 \%$ respectively at $400^{\circ} \mathrm{C}$ ). Phenols and naphthols are present in larger yields than for anthrone, suggesting the cleavage of a single $\mathrm{C}-\mathrm{O}$ bond followed by hydrogenation of the phenoxy (or naphthoxy) group. Ring-reduced derivatives of DNE produced at $350^{\circ} \mathrm{C}$ are absent at $400^{\circ} \mathrm{C}$ and naphthol yields decrease across the same temperature range. These reductions in oxygen compound yields are accompanied by increases in tetralin, naphthalene and alkylbenzene formation.

The product distributions (O : non-O) of reactions of ATTM, Ni-Mo and CoMo-T2 with DNE (Figure 2 and Table 1) distinctly show the latter precursor to be the most favourable for C$\mathrm{O}-\mathrm{C}$ bond cleavage to oxygen-free products. 


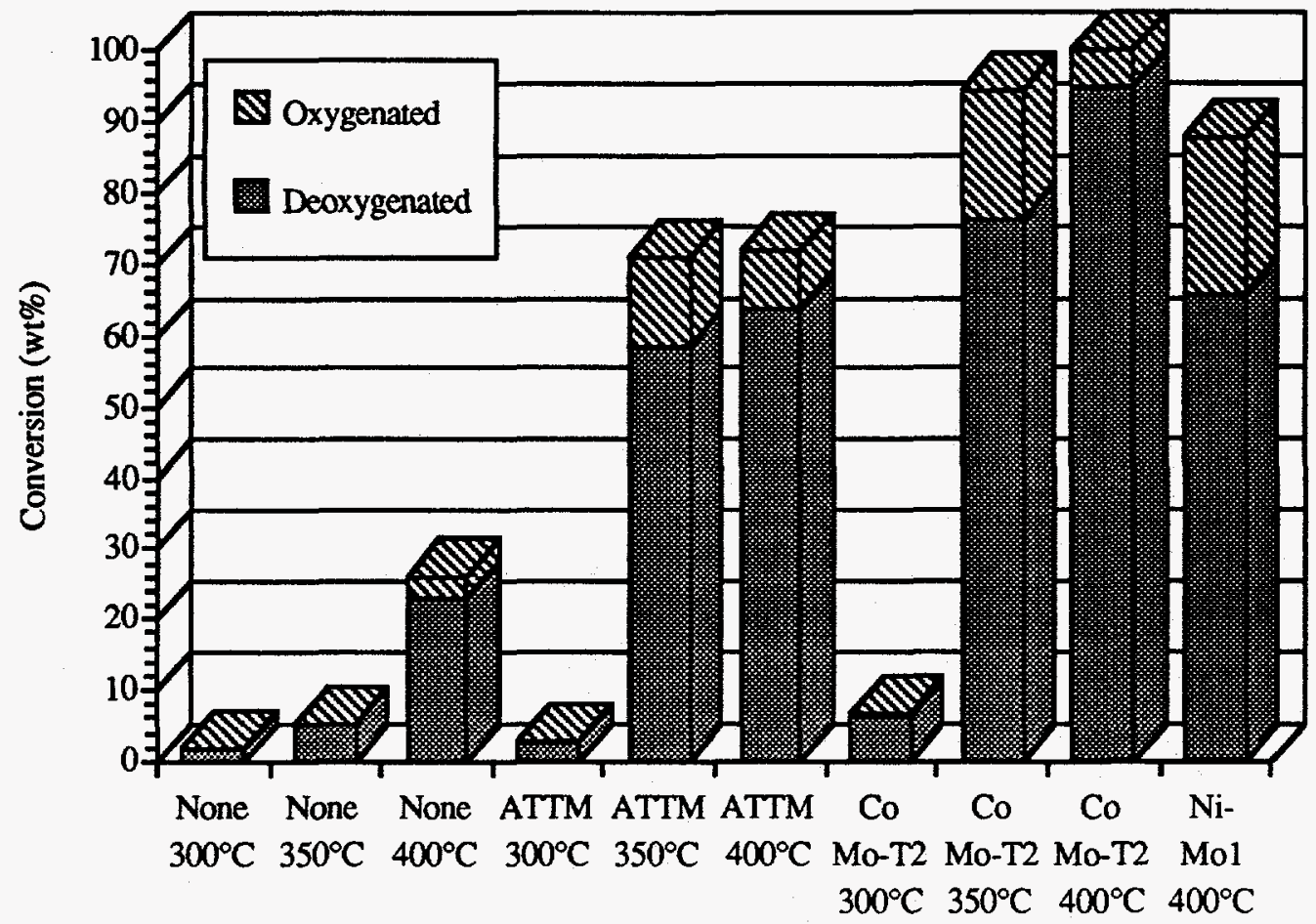

Figure 2. Yield of oxygenated and deoxygenated products from dinaphthyl ether as a function of temperature and catalyst.

Table 1. Product distribution of dinaphthyl ether under liquefaction conditions.

\begin{tabular}{|l|ccc|ccc|cccc|}
\hline React.temp.('C) & 300 & 350 & 400 & 300 & 350 & 400 & 400 & 300 & 350 & 400 \\
Cat. Precursors & None & None & None & ATTM & ATTM & ATTM & Ni-Mo & CoMo-T2 & CoMo-T2 & CoMo-T2 \\
\hline Products(wt\%) & & & & & & & & & & \\
Tetralin & & 1.2 & & 1.3 & 30.5 & 24.4 & 24.6 & 4.4 & 47.2 & 51.6 \\
Naphthalene & 1.9 & 4.1 & 22.9 & 1.4 & 26.1 & 38.3 & 39.1 & 1.9 & 28.6 & 40.2 \\
THDNE & & & & & 7.4 & 6.3 & 12.0 & 0.3 & 7.5 & 0.3 \\
OHDNE & & & & & 1.7 & & 3.2 & & 2.6 & \\
THnaphthol & & & & & 2.3 & 1.0 & 4.1 & & 5.9 & 3.5 \\
2-Naphthol & & & 3.2 & & 0.6 & 0.8 & 2.1 & 0.3 & 1.5 & 0.5 \\
Methylphenol & & & & & 0.3 & & 0.4 & & 0.6 & 0.7 \\
Alkylbenzenes & & & & & 1.9 & 0.9 & 2.0 & & 0.5 & 3.1 \\
Conv. (w1\%) & 1.9 & 5.3 & 26.1 & 2.7 & 70.7 & 71.9 & 87.6 & 6.9 & 94.3 & 100 \\
\hline
\end{tabular}




\section{Xanthene}

In the absence of a catalyst xanthene is totally unreactive. Addition of ATTM or CoMo$\mathrm{T} 2$ produces noticeable reaction at $350^{\circ} \mathrm{C}$ and $400^{\circ} \mathrm{C}$.

At $350^{\circ} \mathrm{C}$ the products from both precursors are phenols, cycloalkyl- and long-chain alkylbenzenes formed by $\mathrm{C}-\mathrm{O}$ and $\mathrm{C}-\mathrm{C}$ bond cleavage. However, at $400^{\circ} \mathrm{C}$ ATTM produces an increase in oxygen-free products with no increase in phenols, although conversion to non-oxygen containing species is low (24.9\%).

Increases in oxygen-free product yields are also achieved with $\mathrm{CoMo}-\mathrm{T} 2$ at $400^{\circ} \mathrm{C}$, but with accompanying increases in phenol formation. This gain in phenols may be attributed to the formation of short-chain (C1-C2) alkylphenols from longer chain alkylphenols, implying that CoMo-T2 favours C-C cleavage over C-OH.

The comparably large conversion to oxygen-free products and phenols reinforces the ability of CoMo-T2 to cleave ether linkages, and inability to remove hydroxyl groups. However, the low conversions of xanthene illustrate the unreactive nature of the starting material.

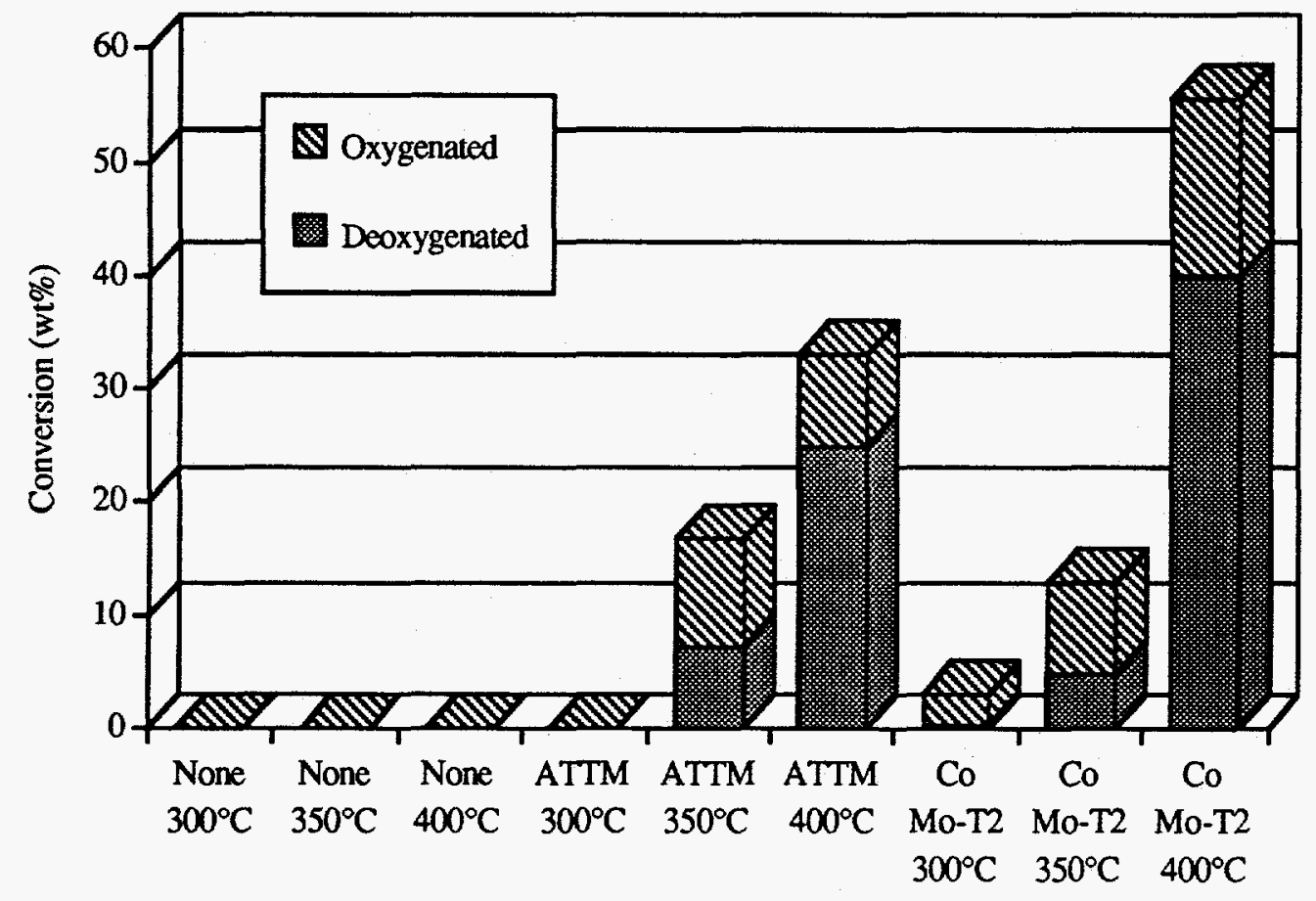

Figure 3. Yield of oxygenated and deoxygenated products of xanthene as a function of temperature and catalyst. 


\section{2,6-Di-t-butyl-4-methylphenol (DBMP)}

Under non-catalytic reaction conditions the conversion of DBMP involves the cleavage of one, or both, of the $t$-butyl groups to produce 2-butyl-4-methylphenol (BMP) and ultimately 4methylphenol $\left(100 \%\right.$ at $\left.400^{\circ} \mathrm{C}\right)$. No reaction occurs at $300^{\circ} \mathrm{C}$ in the absence of a catalyst. When a catalyst is present the removal of the butyl groups becomes more favourable and formation of the above products takes place.

At $350^{\circ} \mathrm{C}$ with ATTM, almost all the starting material has reacted and only a small portion remains as BMP (13.5\%). The major product, 4-methylphenol, then undergoes catalytic hydrogenation and hydroxyl removal to form toluene and methylcyclohexane. At $400^{\circ} \mathrm{C}$ these reactions proceed to a greater extent, resulting in greater yields of both products (46.5\% and $20.2 \%$ respectively).

In the presence of CoMo-T2, DBMP appears to lose both butyl groups so rapidly that no 2-t-butyl-4-methylphenol is isolated, so 4-methylphenol is the only product at $300^{\circ} \mathrm{C}$. At $350^{\circ} \mathrm{C}$ it exhibits some further conversion to methylcyclohexane $(1.6 \%)$ and at $400^{\circ} \mathrm{C}$ toluene and methylcyclohexane are produced.

DBMP is a reactive compound through loss of its butyl groups. However, the hydroxyl group $\mathrm{C}-\mathrm{OH}$ bond is very resistant to reaction and is only cleaved, to a substantial degree, in the presence of the ATTM precursor. CoMo-T2 removes the OH-group, but only to a small extent.

Investigations using the Ni-Mol precursor are not as advanced as those for ATTM and CoMo-T2. Presentation of these results is planned for future articles. 


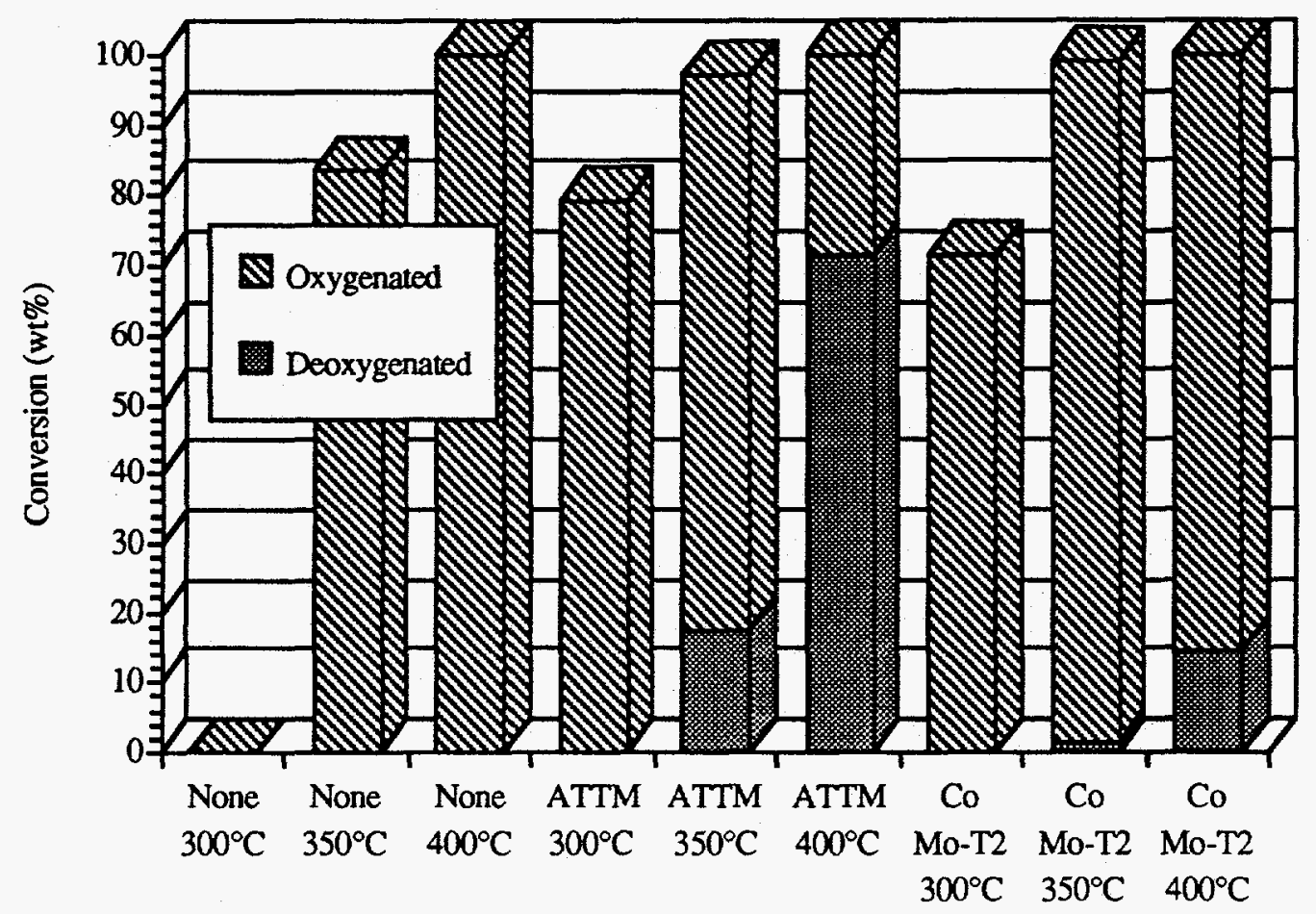

Figure 4. Yield of oxygenated and deoxygenated products of 2,6-di-t-butyl-4-methylphenol as a function of temperature and catalyst.

\section{CONCLUSIONS}

From the non-catalytic data shown there is a clear order of starting material reactivity : 2,6-di-t-butyl-4-methylphenol $>$ anthrone $>$ dinaphthyl ether $>$ xanthene. However, the reactivity order of the oxygen functionalities in the presence of the various catalysts is different. For noncatalytic conditions the order appears to be : carbonyl > aryl-aryl ether » substituted phenol $\approx$ heterocyclic ether. In the presence of ATTM this sequence changes slightly to : carbonyl > substituted phenol $\approx$ aryl-aryl ether » heterocyclic ether and for reactions involving CoMo-T2 the reactivity order appears to be : carbonyl > aryl-aryl ether $>$ heterocyclic ether > substituted phenol.

The contrasting orders of relative catalytic deoxygenation (i.e. the order of deoxygenation that may be attributed to the addition of the catalyst) may be illustrated by subtracting the thermal conversion data from the total conversion of the respective catalytic run. This procedure produces the following orders of deoxygenation: for runs using ATTM, substituted phenol $>$ aryl-aryl ether > carbonyl > heterocyclic ether; for runs using CoMo-T2, aryl-aryl ether > 
heterocyclic ether $\approx$ carbonyl $>$ substituted phenol.

These differences in reactivity order emphasize the effect of the nature of the oxygen functionality on the deoxygenating capabilities of the catalysts and that different catalysts can have different roles in promoting hydrodeoxygenation and reduction, depending on the nature of the starting material. They also highlight the undesirability of phenolic and heterocyclic ether structures in liquefaction systems. Both these structures types are quite unreactive under liquefaction conditions and any reaction has a tendency to form high yields of single-ring phenols.

When applied to coals, these findings suggest that coals differing from each other in the form of which oxygen functional groups are dominant, may show quite different kinds of liquefaction products, depending on which catalyst precursor was chosen.

\section{REFERENCES}

1. C. Song, L. Hou, A. K. Saini, P. G. Hatcher and H. H. Schobert, (1993). Fuel Processing Technology, 34 249-276.

2. R. E. Pauls, M. E. Bambacht, C. Bradley, S. E. Scheppele and D. C. Cronauer, Energy \& Fuels, 4 236-242.

3. C. Burgess, (1994). "Direct Coal Liquefaction: A Potential Route to Thermally Stable Jet Fuel", pp. 167.

4. L. Artok, O. Erbatur and H. H. Schobert, (in press).

5. C. Song, H. H. Schobert and P. G. Hatcher, (1992). Energy \& Fuels, 6 326-328.

6. M. A. Serio, E. Kroo, S. Charpenay, R. Bassilakis, P. R. Solomon, D. F. McMillen, A. Satyam, J. Manion and R. Malhotra, (1993). Proceedings of Contractors' Review Conference: "Coal Liquefaction and Gas Conversion": "The Dual Role of Oxygen Functions in Coal Pretreatment and Liquefaction: Crosslinking and Cleavage Reactions", Pittsburgh, PA, 15-44.

7. S. M. Solum, R. J. Pugmire and D. M. Grant, (1989). Energy \& Fuels, 3 187-193.

8. C. Song and H. H. Schobert, (1992). Am. Chem. Soc. Div. Fuel Chem. Prepr., 3742.

9. L. Huang, C. Song and H. H. Schobert, (1992). Am. Chem. Soc. Div. Fuel Chem. Prepr., 37223.

10. C. Song and H. H. Schobert, (1993). "Novel Bimetallic Dispersed Catalysts for Temperature-Programmed Coal Liquefaction", Penn State University DE-AC2292PC92122-TPR-1.

11. C. Song, D. S. Parfitt and H. H. Schobert, (1993). Catalysis Letters, 21 27-34.

12. L. M. Stock, (1989). Accounts of Chemical Research, 22 427-433.

13. R. Hayatsu, R. E. Winans, R. G. Scott, L. P. Moore and M. H. Studier, (1978). Fuel, $57(2), 541$.

14. J. H. Shinn, (1984). Fuel, 63 (3), 1187. 


\section{Activity and Selectivity of Fe Catalysts from Organometallic and Inorganic Precursors for Hydrocracking of 4-(1-Naphthylmethyl) Bibenzyl}

\section{INTRODUCTION}

Various iron containing catalysts have been investigated for their use in hydroliquefaction of coal ever since Bergius (1) demonstrated the feasibility of the process. Conventional iron $(2,3)$ catalysts have been widely used either unsupported or as catalysts dispersed directly onto coal. Iron catalysts have generally a lower cost and lower environmental detriment than $\mathrm{Mo}, \mathrm{Ni}$ and Co catalyst precursors. The search for active high surface area iron particles has become recently an important part in the development of a cost effective direct coal liquefaction process $(4,5)$.

To examine what determines the activity and selectivity of Fe catalysts for hydrogenation and hydrocracking, various molecular precursors with $\mathrm{Fe}$ in different chemical environments have been tested in this work to help understand the influence of precursor structure and the effect of sulfur addition on the activity and selectivity of resulting Fe catalysts in model reactions of 4(naphthylmethyl)bibenzyl (NMBB). We have examined various precursors, including a thiocubane type cluster $\mathrm{Cp}_{4} \mathrm{Fe}_{4} \mathrm{~S}_{4}$, a cyclopentadienyliron dicarbonyl dimer $\mathrm{Cp}_{2} \mathrm{Fe}_{2}(\mathrm{CO})_{4}$, ferrocene $\mathrm{Cp}_{2} \mathrm{Fe}$, a series of carbonyl precursors including $\mathrm{Fe}(\mathrm{CO})_{5}, \mathrm{Fe}_{2}(\mathrm{CO})_{9}$, and $\mathrm{Fe}_{3}(\mathrm{CO})_{12}$, and superfine iron oxide with average particle size of $30 \AA$ (SFIO).

\section{EXPERIMENTAL SECTION}

Runs with NMBB were carried out in $33 \mathrm{~mL}$ reactor using $0.78 \mathrm{mmol} \mathrm{NMBB}$ in n-tridecane solvent at $400^{\circ} \mathrm{C}$ for $30 \mathrm{~min}$, in the presence of a Fe catalyst precursor $(2.11 \mathrm{wt} \% \mathrm{Fe}$ based on NMBB). Carbonyl precursors were purchased from Aldrich. Precursor synthesis and experimental details may be found elsewhere (6). SFIO sample was provided by Mach I Inc. in Pennsylvania. Catalyst samples for BET and XRD analysis were prepared in similar reactors from ca. $1 \mathrm{~g}$ precursor and $4 \mathrm{~g}$ tridecane at $400^{\circ} \mathrm{C}$ under $6.9 \mathrm{MPa} \mathrm{H}_{2}$ pressure for $30 \mathrm{~min}$. XRD data were obtained from a Scintag I (Scientific Computer and Instruments, USA). Surface area measurements were conducted using a Quantachrome Autosorb I Gas Sorption system.

1. F. Bergius and Billiviller, German Patent No. 301, Coal Liquefaction Process, (1919), 231.

2. P.A. Montano, A.S. Bommannavar and V. Shah, Fuel, Vol. 60, (1981), 703.

3. T. Suzuki, H. Yamada, P.L. Sears, and Y. Watanabe, Energy Fuels, Vol. 3, (1989), 707.

4. A.V. Cugini, D. Krastman, R.G. Lett and V. Balsone, Catalysis Today, Vol. 19, (1994), 395-408.

5. F. Derbyshire, Energy and Fuels, Vol. 3 (1989), 273-77.

6. a) E. Schmidt and C. Song, Prepr. Pap. - Am. Chem. Soc., Div. Fuel Chem., No. 35, (1990) 733-737.

b) C. Song, E. Schmidt and H.H. Schobert, DOE Coal Liquefaction and Gas Conversion, Contractors' Review Meeting in Pittsburgh, (September 7-8, 1994), 593-604. 


\section{RESULTS AND DISCUSSION}

\subsection{Conversion of NMBB}

The initial stage of a catalytic reaction involves catalyst activation at elevated temperatures, depending on the type of catalyst precursor. It is known $(7,8,9)$ that some precursors like metal carbonyls require the addition of sulfur for sufficient activity. There seems (10) to be consensus that the sulfides of the transition metals are more active in catalytic hydroliquefaction than their oxides. The reason for this remains unclear. The activation reaction is difficult to perform and iron carbonyls tend to form less reactive iron carbides and oxides (11) during the activation process. The present results in Tables 2 and 3 revealed several interesting trends. Even the catalysts without sulfur can display certain activity. The particles from $\mathrm{Cp}_{2} \mathrm{Fe}_{2}(\mathrm{CO})_{4}$ showed the highest activity among all the precursors examined in the absence of added sulfur. The activity of catalysts from $\mathrm{Fe}$ carbonyls decreased with increasing number of irons in the carbonyl compounds: $\mathrm{Fe}(\mathrm{CO})_{5}>\mathrm{Fe}_{2}(\mathrm{CO})_{9}>\mathrm{Fe}_{3}(\mathrm{CO})_{12}$; adding sulfur increased their activity but their activities rank the same both with and without sulfur addition.

Surprisingly, $\mathrm{Cp}_{4} \mathrm{Fe}_{4} \mathrm{~S}_{4}$ exhibited the lowest activity, although it has the S-to-Fe ratio closest to pyrrhotite $\left(\mathrm{Fe}_{1-\mathrm{x}} \mathrm{S}\right.$, where $\mathrm{X}=0$ to 0.12$)$ which is thought to be the active phase. The nanoscale SFIO particles performed at an activity level similar to that of $\mathrm{Fe}_{2}(\mathrm{CO})_{9}$ in the absence of sulfur, but afforded the highest NMBB conversion when $\mathrm{S}$ was added. Ferrocene is more effective in hydrocracking reactions of NMBB than the inorganic iron complex $\mathrm{FeSO}_{4} \cdot 7 \mathrm{H}_{2} \mathrm{O}$ (Table 3). Sulfur added to iron sulfate had the expected beneficial effect on NMBB conversion. But sulfur added to ferrocene decreased the activity of resulting catalyst. The other iron containing organometallic complex that showed a similar trend in conversion after sulfur addition was $\mathrm{Cp}_{2} \mathrm{Fe}_{2}(\mathrm{CO})_{4}$. Both complexes have cyclopentadienyl ligands as common features. Another precursor with $\mathrm{Cp}$-functionalities and sulfur in the precursor molecule $\left(\mathrm{Cp}_{4} \mathrm{Fe}_{4} \mathrm{~S}_{4}\right)$ showed very low activity too. There is apparently a negative correlation between the conversion of iron containing complexes and the presence of cyclopentadienyl/sulfur units.

7. O. Yamada, T. Suzuki, J. Then, T. Ando and Y. Watanabe, Fuel Process. Technol., Vol. 11, (1985), $297-311$.

8. T. Suzuki, T. Ando and Y. Watanabe, Energy and Fuels, Vol. 1, (1987), 299-300.

9. L. Artok, A. Davis, G.D. Mitchell and H.H. Schobert, Energy Fuels, Vol. 7, (1993), 67-77.

10. S. Weller, Energy Fuels, Vol. 8, (1994), 415-420.

11. D. Herrick, J. Tierny, I. Wender, G.P. Huffamn and F.E. Huggins, Energy and Fuels, Vol. 4, (1990), 231. 
Table 2. Effect of Fe containing catalyst precursors on NMBB hydrocracking at $400^{\circ} \mathrm{C}$.

\begin{tabular}{|l|c|c|c|c|c|c|c|c|}
\hline $\begin{array}{l}\text { Catalyst } \\
\text { Precursors }\end{array}$ & $\mathrm{CP}_{2} \mathrm{Fe}_{2}(\mathrm{CO})_{4}$ & $\mathrm{Fe}(\mathrm{CO})_{5}$ & $\begin{array}{c}\mathrm{Fe}_{2}(\mathrm{CO}) \\
9\end{array}$ & $\begin{array}{c}\mathrm{Fe}_{3}(\mathrm{CO})_{1} \\
2\end{array}$ & $\begin{array}{c}\mathrm{Fe}(\mathrm{CO})_{5} \\
+\mathrm{S}\end{array}$ & $\begin{array}{c}\mathrm{Fe}_{2}(\mathrm{CO}) \\
9 \\
+\mathrm{S}\end{array}$ & $\begin{array}{c}\mathrm{Fe}_{3}(\mathrm{CO})_{12} \\
+\mathrm{S}\end{array}$ & $\begin{array}{c}\mathrm{Cp}_{2} \mathrm{Fe}_{2}(\mathrm{CO})_{4} \\
+\mathrm{S}\end{array}$ \\
\hline Conv, wt \% & $\mathbf{6 2 . 2}$ & 45.6 & 24.7 & 22.1 & 61.2 & 51.5 & 45.7 & 21.3 \\
\hline Prod, mol \% & & & & & & & & \\
\hline Benzene & 0.6 & & & & 1.3 & & 0.7 & 0.9 \\
\hline Toluene & 1.6 & 1.3 & 0.8 & 1.5 & 2.3 & 2.3 & 1.9 & \\
\hline p-Xylene & 0.5 & 0.2 & 0.2 & 0.3 & 0.8 & 0.4 & 0.7 & 0.2 \\
\hline Tetralin & 8.5 & 4.2 & 2.2 & 2.0 & 2.6 & 1.5 & 2.0 & 0.3 \\
\hline Naphthalene & 38.1 & 42.8 & 20.3 & 23.3 & 67.8 & 47.8 & 46.6 & 20.4 \\
\hline 2-MTHNa & & & & & & & & \\
\hline 1-MTHN & 0.8 & 0.3 & 0.4 & & & & & \\
\hline 2-MN & 0.2 & & & & 1.3 & 1.1 & 0.8 & 0.1 \\
\hline 1-MN & 2.5 & 2.6 & 1.0 & 1.6 & 5.3 & 3.7 & 3.4 & 1.1 \\
\hline BB & 4.0 & 3.6 & 1.6 & 1.8 & 7.6 & 6.7 & 5.5 & 1.5 \\
\hline Benzyl- & 0.3 & 0.1 & & & & & & 0.2 \\
\hline naphthlene & & & & & & & & \\
\hline 4-MBB & 40.1 & 35.7 & 20.3 & 16.2 & 52.7 & 41.1 & 33.6 & 18.5 \\
\hline TH-NMBB & 14.4 & 0.8 & 1.4 & & & & & 0.3 \\
\hline
\end{tabular}

aMethyltetrahydronaphthalene; $b_{\text {methylnaphthalene; }} c_{\text {bibenzyl; }} d_{\text {methylbibenzyl; }} e_{\text {tetrahydro-NMBB. }}$ 
Table 3. Effect of Fe precursors with different ligands on NMBB hydrocracking at $400^{\circ} \mathrm{C}$.

\begin{tabular}{|l|c|c|c|c|c|c|c|c|}
\hline $\begin{array}{l}\text { Catalyst } \\
\text { Precursors }\end{array}$ & $\begin{array}{c}\text { Non- } \\
\text { catalytic }\end{array}$ & $\begin{array}{c}\text { Superfine } \\
\mathrm{Fe}_{2} \mathrm{O}_{3}\end{array}$ & $\begin{array}{c}\text { Superfine } \\
\mathrm{Fe}_{2} \mathrm{O}_{3}+\mathrm{S}\end{array}$ & $\begin{array}{c}\mathrm{FeSO}_{4} \mathrm{x} \\
7 \mathrm{H}_{2} \mathrm{O}\end{array}$ & $\begin{array}{c}\mathrm{FeSO}_{4} \times \\
7 \mathrm{H}_{2} \mathrm{O}+\mathrm{S}\end{array}$ & $\begin{array}{c}\mathrm{Cp}_{2} \mathrm{Fe} \\
\mathrm{Cp}_{2} \mathrm{Fe} \\
+\mathrm{S}\end{array}$ & $\mathrm{Cp}_{4} \mathrm{Fe}_{4} \mathrm{~S}_{4}$ \\
\hline Conv, wt \% & $\mathbf{3 . 9}$ & $\mathbf{2 7 . 1}$ & $\mathbf{7 8 . 2}$ & $\mathbf{3 . 7}$ & $\mathbf{2 3 . 9}$ & $\mathbf{1 5 . 8}$ & $\mathbf{9 . 6}$ & 11.7 \\
\hline Prod, mol \% & & & & & & & & \\
\hline Benzene & 0.6 & 0.2 & 0.5 & & & & & 2.5 \\
\hline Toluene & 0.3 & 1.3 & 1.9 & & 1.3 & 1.6 & 1.1 & \\
\hline p-Xylene & & 0.3 & 0.7 & & & & & \\
\hline Tetralin & 0.2 & 3.0 & 4.0 & & 0.6 & 0.4 & 0.3 & \\
\hline Naphthalene & 0.6 & 16.4 & 64.1 & 4.5 & 24.0 & 13.8 & 10.3 & 10.9 \\
\hline 2-MTHNa & & & 0.2 & & & & & \\
\hline 1-MTHN & & 0.5 & 0.4 & & & & & \\
\hline 2-MNb & & & 1.4 & & & & & \\
\hline 1-MN & & & 5.8 & & 1.5 & 5.6 & 0.5 & 0.1 \\
\hline BBc & & 1.0 & 8.9 & 0.6 & 2.5 & 2.6 & 0.6 & 0.4 \\
\hline Benzylnaphthlene & 0.9 & & & & & & & \\
\hline 4-MBB & 1.3 & 17.4 & 59.6 & 2.6 & 19.1 & 9.4 & 7.4 & 10.8 \\
\hline TH-NMBBe & & 7.3 & 5.5 & & & & & \\
\hline
\end{tabular}

${ }^{a}$ Methyltetrahydronaphthalene; ${ }{ }_{m}$ ethylnaphthalene; ${ }^{c}$ bibenzyl; ${ }^{d}$ methylbibenzyl; ${ }{ }_{\text {tetrahydro-NMBB. }}$

To better understand the relationship between catalyst composition and catalytic activity, surface area and XRD measurements were carried out. The surface area of freshly generated catalyst particles was measured and the phase identified through X-ray diffraction. Our investigation of in situ generated iron catalyst from organometallic precursor revealed higher surface areas for pyrrohtite than magnetite particles. From XRD-measurement, it was found that iron carbonyl was transformed at $400{ }^{\circ} \mathrm{C}$ into magnetite $\mathrm{Fe}_{3} \mathrm{O}_{4}$. Sulfur added to $\mathrm{Fe}(\mathrm{CO})_{5}$ yields pyrrohtite as black material. Generally iron sulfides have higher surface areas than magnetite. The effect of sulfur addition to iron carbonyls on the surface area is illustrated in Table 4. 
Table 4. BET Surface area and phase of activated catalysts.

\begin{tabular}{|l|c|c|c|}
\hline Precursor Molecule & $\begin{array}{c}\text { BET Surface } \\
\text { area } \\
\mathbf{m}^{2 / \mathrm{g}}\end{array}$ & $\begin{array}{c}\text { Meso Pore } \\
\text { Surface Area } \\
\mathbf{m}^{2 / g}\end{array}$ & $\begin{array}{c}\text { Phase Pattern } \\
\text { from } \\
\text { XRD }\end{array}$ \\
\hline $\mathrm{Fe}(\mathrm{CO})_{5}$ & 3.22 & 3.22 & $\mathrm{Fe}_{3} \mathrm{O}_{4}$ \\
\hline $\mathrm{Fe}_{2}(\mathrm{CO})_{9}$ & 7.73 & 7.73 & $\mathrm{Fe}_{3} \mathrm{O}_{4}$ \\
\hline $\mathrm{Fe}_{3}(\mathrm{CO})_{12}$ & 17.6 & 17.6 & $\mathrm{Fe}_{3} \mathrm{O}_{4}$ \\
\hline $\mathrm{Fe}(\mathrm{CO})_{5}+\mathrm{S}$ & 1.56 & 1.54 & $\mathrm{FeS}$ \\
\hline $\mathrm{Fe}_{2}(\mathrm{CO})_{9}+\mathrm{S}$ & 3.58 & 3.45 & $\mathrm{FeS}$ \\
\hline $\mathrm{Fe}_{3}(\mathrm{CO})_{12}+\mathrm{S}$ & 2.93 & 2.93 & $\mathrm{FeS}$ \\
\hline $\mathrm{Ferrocene}_{3}+\mathrm{S}$ & 21.7 & 20.5 & $\mathrm{FeS}$ \\
\hline $\mathrm{Cp}_{4} \mathrm{Fe}_{4} \mathrm{~S}_{4}$ & 11.39 & 9.33 & $\mathrm{FeS}$ \\
\hline $\mathrm{Fe}_{2} \mathrm{O}_{3}$ & 228 & 228 & $\ldots$ \\
\hline
\end{tabular}

Surprisingly, higher surface areas can be generated from higher iron carbonyl clusters. The BET surface area increases dramatically with increasing number of inter iron bonds. A similar trend can be observed when sulfur is added to the corresponding iron carbonyls. However, pyrrohtite coming from $\mathrm{Fe}$ carbonyls has a substantially lower surface area than the analogue generated from ferrocene and sulfur. Even the sparingly soluble $\mathrm{Cp}_{4} \mathrm{Fe}_{4} \mathrm{~S}_{4}$ yields after thermal activation higher surface area material than most iron carbonyls which are more soluble in hydrocarbons and are expected to lead to higher dispersion. The XRD-pattern reveals pyrrohtite as main product. This excludes iron carbide as the activity inhibiting material. However, the microstructure can be influenced by minute traces of impurities. Further elemental analysis will help clarify this issue.

\subsection{Distribution of products from NMBB}

Hydrocracking of NMBB yields three product categories that can be explained by the cleavage of the bonds between the aromatic moieties. Those coming from hydrocracking reactions form the major pool of reaction products, followed by hydrogenation and isomerization products. As can be seen from Tables 2 and 3, all iron containing catalyst precursors give a similar ratio of main products. It is apparent that ferrous catalysts cleave NMBB preferably in position $\alpha$. Increasing conversion leads in most experiments to a proportional increase in the ratio of major products. The following compounds can be found as main products: naphthalene, 4$\mathrm{MBB}$, bibenzyl and tetralin. 
Farcasiu et al. $(12,13,14)$ suggested a reaction mechanism in which the first stage consists of the formation of a radical cation. The loss of electron density leads to a weakened $\alpha$-bond which can then be broken relatively easily. This is in contrast to model studies in which phenylcontaining compounds undergo preferably $\beta$-cleavage (15).

In the work of Penn and Wang (15) radical cations were generated in the mass spectrometer under a variety of conditions which had little impact on the bond cleavage pathway. Preference for $\beta$-cleavage was explained by resonance stabilization of the intermediates. Both intermediates are resonance stabilized. Thermochemical calculations (16) show that reaction pathway $\beta$ is 30 $\mathrm{kcal} / \mathrm{mol}$ lower for both neutral and radical cationic species than pathway $\alpha$. In contrast, neither of the intermediates resulting from bond $\alpha$ cleavage is stabilized. However, in the presence of a catalyst, the major reaction pathway mainly involves the cleavage of bond $\alpha$.

\subsection{Possible reaction mechanism}

The structure of NMBB influences the cleavage pathway. Catalyst particles act as hydrogen transfer agents and stabilize the intermediate radical. They prevent undesirable recombination of the free radicals to polymeric material. Naphthalene and 4-methylbibenzyl are formed predominately in catalyzed reactions, indicating that bond $\alpha$ in NMBB is the most reactive unit in the Fe-catalyzed runs. However, different ligand environment and oxidation state of the precursor molecule can reverse the observed preference for bond $\alpha$ cleavage (e.g. $\mathrm{MoCl}_{3}$ ). Related work (17) investigated the reaction mechanism of bond scission of naphthyl-derivatives and proposed the addition of a hydrogen radical to the ipso position of the naphthyl-unit to generate a relatively stable benzylic radical. Our data, as shown in Tables 1 and 2 support the hypothesis that all iron containing catalyst precursors induce preferably the scission of bond $\alpha$ in NMBB. It is believed (18) that strong hydrogenation catalysts show higher selectivity towards $\alpha$ cleavage than less active iron catalysts. High catalytic activity is accompanied by rich hydrogen supply adsorbed on the catalyst surface. Model compounds with aromatic ipso positions are prone to subsequent reactions with hydrogen radicals, leading to hydrogenation products. The less active iron catalysts are not capable of multiple hydrogen transfer during the short contact time between NMBB and model compound. Thus cleavage of NMBB occurs with higher

12. M. Farcasiu and C. Smith, Prepr. Pap. - Am. Chem. Soc., Div. Fuel Chem., No. 35, (1990) 404-13.

13. M. Farcasiu and C. Smith, Fuel Processing Technology, No. 29, (1991), 199-208.

14. M. Farcasiu and C. Smith and E.P. Ladner, Prepr. Pap. - Am. Chem. Soc., Div. Fuel Chem., No. 36, (1991), 1869-77.

15. J.H. Penn and J.H. Wang, Energy Fuels, Vol. 8, (1994), 421-425.

16. H.F. Ades, A.L. Companion, K.R. Subbaswamy, Prepr. Pap. - Am. Chem. Soc., Div, Fuel Chem., Vol. 36, (1991) 420-430.

17. J.A. Franz, D.M. Camaioni, M.S. Alnajjar, T. Autrey and J.C. Linehan, Prepr. Pap.-Am. Chem. Soc., Div. Fuel Chem., No. 40, (1995), 203-7.

18. M.T. Klein, C.F. Foley, D.T. Walter and S.M. Casey, Coal Liquefaction and Gas Conversion, Contractors' Review Meeting in Pittsburgh, (September 7-8, 1994), 565-78. 
selectivity. The structure of the catalyst precursors and the sulfur addition affect the reactions on the surface of in situ generated catalysts.

\section{CONCLUSIONS}

Some iron containing catalysts have higher activity in the sulfur-free form, contrary to conventional wisdom. Adding sulfur to Fe precursors with Cp-ligands decreased the activity of the resulting catalyst. This is in distinct contrast to the cases with iron pentacarbonyl and superfine $\mathrm{Fe}_{2} \mathrm{O}_{3}$, where $\mathrm{S}$ addition increased their catalytic activity substantially. A positive correlation between sulfur addition and increased activity can be seen, but a reversed trend between Fe cluster size and hydrocracking conversion could be observed, for carbonyl-type $\mathrm{Fe}$ precursors. It is apparent that the activity and selectivity of Fe catalysts for NMBB conversion depends strongly on both the type of ligand environment, the oxidation state and the number of intermetal bonds in the molecular precursor. 